\title{
Selling the studio style to students: A qualitative study
}

\author{
Matthew Wilcox and Jacquelyn J. Chini \\ Department of Physics, University of Central Florida, 4111 Libra Drive, Orlando, FL, 32816
}

\begin{abstract}
Students in studio classes, a student-centered approach to teaching physics, may exhibit resistance to the reformed strategies used in this class format. Instructors of these classes may try to decrease resistance by increasing student agreement with the class format. What should instructors talk about, and how should they hold the conversation to effectively gain student agreement? Based on student interview responses, we report on the student perspective for effective means of gaining agreement. We describe the discussion topics and modes of discussion (e.g. lecture, class discussion) which students consider effective practices for gaining their agreement. First, we find that student agreement with reformed pedagogies at the start of the semester was primarily influenced by their experiences and opinions developed from prior classes and their agreement throughout the semester was primarily influenced by their experiences in their current physics class. When asked what would potentially be an effective strategy to gain student agreement, student and instructor responses suggested an evidence-based class discussion. However, instructors indicated they might not have evidence-based material to reference in this type of conversation.
\end{abstract}

\section{INTRODUCTION}

Students in a studio style introductory physics class, which combines lecture, labs, and problem solving in one interactive, student-centered environment, may not expect the reformed strategies instructors use as part of this class [1]. When the class style does not meet their expectations, students may feel dissatisfied with the class [2] and thus, exhibit resistance to the reformed strategies the instructor may implement. Numerous studies have found that instructors cite student resistance as a barrier to the implementation of research-based instructional strategies (RBIS; the studio style for example) [3, 4] but they do little to describe how to reduce student resistance. When students value active learning, they are less resistant and more participatory in active learning [5] than students who do not value it. So, it is important to get students to value or at least agree with the reformed format of studio classes if instructors hope to lessen student resistance, thus making it easier to successfully implement the effective RBIS.

As part of a larger project investigating student agreement, we report the potentially effective strategies suggested by students and instructors for discussing the class format with students to get them to buy-in to the studio physics class. We operationalize student agreement as the difference between what a student perceives is occurring in class and what they would prefer in their ideal class. Low differences correspond to high agreement. Previous research has found that describing the class format can influence students' expectations of a reformed class [1]. Our larger project [6] and another study [7] have shown that student perceptions of a discussion about the class format positively influenced their response to the reformed format. However, quantitative analyses have not determined specific strategies to use during these discussions. For example, although Finelli et al. [7] find that explanation and facilitation strategies increase student response to reformed instruction, they do not specify how exactly to use explanation or facilitation strategies or which elements of those strategies are effective. In this study, we investigate specific discussion methods and modes to determine which could effectively gain student agreement.

\section{METHODS}

We conducted hour-long, semi-structured interviews with five instructors and nine students from three universities. We interviewed two students from four instructors and one student from the fifth. All students had little previous studio class experience and were around 20 years old. Five students were women and four were men. Six of the nine students had a racial and ethnic background that is well represented in STEM (White non-Hispanic or Asian). Six of the nine students were in their first or second year of college while the other three students were in their third year or more. Many of the instructors were White non-Hispanic men, younger than 40 , with two or fewer semesters of studio teaching experience; Instructor 1 is a woman, and instructor 3 has 11 semesters of studio teaching experience and did not identify with a race/ethnicity.

The primary goals of these interviews were to determine: a) what actually influenced student agreement with a reformed class format; and b) additional instructor strategies that could potentially influence student agreement. During the student interviews, we asked students what class activities they agreed with and disagreed with at the start of the semester and their rationales for this (dis)agreement. Then, we asked if their agreement changed for any class activities and what influenced that change. We also wanted to know what instructor strategies could influence the students' agreement. During the interview, we provided students and instructors with a list of the strategies shown in Table I that an instructor might use to gain student agreement. Then we asked the students and instructors which of the listed strategies they felt would be effective at gaining student agreement. 
TABLE I. Instructor strategies to gain student agreement and the number of students and instructors stating the strategy would be effective at gaining student agreement ( 8 of 9 students reached that portion of the interview). Only strategies discussed in this paper are presented here.

\begin{tabular}{lcc}
\hline \multicolumn{1}{c}{ Strategy } & Definition & $\begin{array}{c}\text { Students - Instructors } \\
\text { Stated Effectiveness }\end{array}$ \\
\hline Methods & (8 max - 5max) \\
\hline $\begin{array}{c}\text { Advantages of Engagement } \\
\text { Comparison Between Reformed } \\
\text { and Traditional Classes }\end{array}$ & $\begin{array}{c}\text { Discussing the advantages of engaging in this class. A mention } \\
\text { of how being engaged will be good for the students. } \\
\text { Discussing the advantages of using research-based instructional } \\
\text { strategies or the disadvantages of a traditional class. } \\
\text { Appealing to the students' emotions or experiences so that the } \\
\text { discussion relates directly to the student }\end{array}$ & $4-0$ \\
Evidence Based Discussion & $\begin{array}{r}\text { Appealing to research data or results about student learning in } \\
\text { the class format. Making claims based in fact. }\end{array}$ & $5-0$ \\
\hline "Modes" of Conversation & $\begin{array}{c}\text { Talking to the students with little to no student input. } \\
\text { Lecture }\end{array}$ & $6-4$ \\
\hline Class Discussion/Activity & Discussion between students or discussion guided by instructor. & $4-2$ \\
\hline \hline
\end{tabular}

TABLE II. Other influences on student agreement identified from student interviews. Only influences discussed in this paper are presented here.

\begin{tabular}{cc}
\hline Student Interview Code & Definition \\
\hline $\begin{array}{c}\text { Prior Knowledge/ Experiences/ } \\
\text { Opinions }\end{array}$ & $\begin{array}{c}\text { Agreement based on what students know of themselves, based on past experiences in } \\
\text { other classes or based on previously developed opinions of what makes an effective class. } \\
\text { Agreement based on experiences with their current class (i.e. whether they feel an aspect } \\
\text { of the class is working for them or not based on their experiences/opinions of it). }\end{array}$ \\
\hline \hline
\end{tabular}

The list of strategies was developed from the Science Education Initiative's "First Day Framing" materials [8]. We categorized the strategies as either a "method" or a "mode", as shown in Table I. A "method" is an argument that an instructor makes; it can be considered as the substance of the discussion. Instructors may use multiple methods in the same argument. For example, an instructor may use the "comparison" method alone or provide factual evidence for the argued comparison using the "evidence" method in addition to the "comparison" method. The "mode" is the means of having the discussion. Previously, we found evidence that instructors correctly understood the strategies through validity interviews conducted as part of our larger project and found that the strategies covered the range of activities they used to generate student agreement [6]. For students, the interviewer described each strategy and gave examples so that students could understand what each strategy entailed. For brevity, we excluded from Table I instructor strategies for which few students or instructors stated their potential effectiveness. These are "extended example" and "try and see" methods in addition to "reading/syllabus", "audio/video", "reminders throughout the semester", and "rewarding appropriate behavior" modes. For information on these strategies see Wilcox [6].

We analyzed transcripts of the student and instructor interviews via thematic analysis [9]. During this analysis, we identified several themes related to influences on student agreement that we did not identify in the First Day Framing materials; these emergent strategies are listed in Table II. For brevity, we excluded from Table II other influences not discussed further in this paper; these are "Method-Benefit", "No Instructor Effect", and "Trust/Faith in the Instructor". For information on these strategies, see Wilcox [6].

As students discussed the class activities they agreed with, we asked them if anything the instructor did influenced that agreement. We coded their responses to this open-ended section of the student interview to determine which instructor strategies were salient and effective. We investigated the reliability of the coding of the student interviews by conducting an inter-rater reliability (IRR) process. After a training process (which included coding a sample transcript), the primary graduate student researcher of this project and another graduate student from outside of the project independently coded the same student interview, which neither graduate student had read before. We measured IRR 
using Cohen's Kappa [10] by counting the coding agreements and disagreements across all codes between the two researchers for each major question in the interview. The Cohen's Kappa for this transcript was 0.81 , indicating strong agreement. We did not investigate IRR for the instructor interviews because instructors only selected the strategies from a provided list, like verbally responding to a survey.

\section{FINDINGS}

\section{A. Experience influences agreement}

All participants discussed prior knowledge, experiences, and opinions as the primary influences on their agreement at the start of the semester and current class experiences as the primary influence on their change in agreement throughout the semester. Few students mentioned that a specific instructor strategy influenced their agreement other than the "lecture mode" strategy, which seven students mentioned. When instructors described the class format using the "lecture mode", students could then decide if they agreed with the description of the class. Student 4A said the following about how the instructor's explanations and her prior opinions both informed her disagreement with the time spent lecturing in class: "The way that he presented it [the lecture activity] to us, [lecture] was only gonna be like 20 minutes of class. Um, which, and I was kind of hoping for a little bit more lecture because physics is hard, and I need instruction with it." This shows that the student was given the opportunity to compare her opinion about her preferred class format with the instructor's planned course format.

The previous quote illustrates how prior experiences influence student agreement at the start of the semester. Experiences in the class during the semester also influence student agreement throughout the semester. During the semester, student responses indicate that their agreement with the class format is dependent upon how well the students are doing in the class. For example, student 5A said of the time spent on student presentations: "So I just assumed that since we didn't really do it, and I'm doing fine, that the amount of time that we're spending doing it probably is fine." Student 3B says her agreement with the importance placed on activities that occur in the classroom increased over the semester, "because I just thought about, like, what we did in class, um, and how that tied to doing well in the class..."

The student responses indicate that their agreement with the class format was largely dependent on their previous knowledge/experiences/opinions developed before the semester or their current experiences in their physics class. Other studies have also found that student experience was the primary way that students determined if they agreed with active learning [5].

\section{B. An evidence-based class discussion could be effective}

Although students in our study did not feel their instructor influenced their agreement, this does not imply that ALL instructor strategies (especially those not used by the instructors) are ineffective. We asked instructors and students which of the strategies shown in Table I they felt would be effective in gaining student agreement. The results are shown in the right column of Table I.

Students and instructors agreed that an evidence-based discussion could be effective at gaining student agreement. Six of eight students indicated this method would be effective. Student 5A said, "I would have been more swayed if there was evidence based discussions that actually had clear evidence of how this [class format] would be beneficial towards all of us learning. "Student 1A stated that a factual discussion about how people learn would help her agree with the class format. When asked what would be the best way to get her to agree with the class format, she said, "Probably discussion of how people learn, in all honesty. Just because, if you're trying to tell, if you're telling how other people learn, that would convince you more on how studio lab is run." Student $3 \mathrm{~A}$ said that an evidence-based discussion would only be effective if it occurred in the context of a student focused discussion as well. This student said, "Logic is super important. But also, you know, um, being able to just, like, talk to the students as well, like, relating to their experiences, relating to the emotions, you know, regarding to the class. It also has to like, take part."

Four of the five instructors also agreed that an evidencebased discussion could be effective. Instructor 1 indicated that evidence would be helpful for specific topics and she also saw ways to turn the evidence into a learning opportunity. She said, "I think it would be interesting for like specific types of activities, like maybe not for the class as a whole but like if a specific topic, there's been something shown, this one activity works really well to help students learn it. So, evidence that that works." Like instructor 1, instructor 5 also would have liked to use an evidence-based discussion. He said, "One thing that I would like to do is give a better evidence-based discussion, but we just really don't have a lot of evidence built up from our own implementation yet." Instructor 4 did use an evidence-based discussion and he felt it got positive results. In the interview, he mentioned that the discussion seemed to improve his class' test results, which made him believe that the discussion increased student agreement with the class format.

While there was little consensus among the instructors regarding the format of the discussion, students (six out of eight) agreed that a class discussion/activity would be an effective means of talking about the class format and why students should agree with it. Student 2B said, "I'm actually persuaded by class discussion and activity, because this gives us a chance to kind of question why it kind of works the way that it does. "Student 3B states that a class discussion is effective because it allows her to think about the class format in the context of her peers. She says, "I can compare, you know, how I feel to how they feel about it, um, you know, see if everyone is, like, on the same page." These students see that the benefit of a class discussion is that it gives them an 
opportunity to understand and question the class format in a way that they could not do if they were simply told how the class will function. Research in instructional communication provides support that a class discussion is an effective way to build knowledge; "Information can be accumulated, but knowledge and understanding are only generated by working with information, selecting from it, organizing it, arguing for its relevance." (p. 67) [11]. These activities are most easily facilitated in the "class discussion" mode.

\section{Instructors may not have evidence-based materials}

As instructor 5 stated, “we just really don't have a lot of evidence built up from our own implementation yet," some instructors may not use an evidence-based discussion because they do not have evidence-based materials to refer to. Similarly, Instructor 1 said, "I don't know that evidencebased things, I don't always...I didn't usually have an exact citation..." She later indicated that if she had evidence-based materials she might have used them in her class. Previous research has found that instructors use evidence when making instructional decisions [12]. Some instructors use formal, statistical analyses. Instructors may obtain such formal evidence-based material by administering conceptual inventories or attitudinal surveys. Other instructors used evidence from conversations with students and their own notes taken during class to inform their instructional decisions. Instructors could use these types of evidence to explain to their students why they chose to teach in the reformed manner.

\section{CONCLUSIONS AND IMPLICATIONS}

In this study, we investigated the potentially effective strategies that students and/or instructors believed would be effective strategies at gaining student agreement if employed by instructors. From interviews with students and instructors, we found that they both believed that an evidence-based discussion would be an effective method to gain student

[1] J. D. Gaffney, A. L. H. Gaffney and R. J. Beichner, Phys. Rev. Special Top.-Phys. Ed. Res. 6, 1 (2010).

[2] J. J. Chini, J. D. Gaffney and A. Al-Rawi, in Proceedings of the Physics Education Research Conference, Portland, OR, 2013.

[3] C. Turpen, M. H. Dancy and C. Henderson, Phys. Rev. Phys. Ed. Res. 12, 1 (2016).

[4] C. Henderson and M. H. Dancy, Phys. Rev. Special Top.Phys. Ed. Res. 3, 2 (2007).

[5] K. M. Cooper, M. Ashley and S. E. Brownell, J. of Microbiol. and Biol. Ed. 18, 2 (2017).

[6] M. Wilcox, Ph.D. Dissertation, University of Central Florida, 2018.

[7] C. J. Finelli, et al., J. of Col. Sci. Teach. 47, 5 (2018). agreement with a reformed class format. Students agreed that talking about the class format and why they should agree would best be done through a class discussion or activity which allows them to question the class format and understand it with the aid of their peers. Although instructors felt that an evidence-based discussion would be effective, few of them used that method in their class. Responses from two instructors suggest that they may not have used an evidence-based discussion because they did not have such materials.

Moving forward, instructors or departments should collect evidence towards studio's effectiveness so that instructor's may use this evidence when introducing the class format to their students. If there is no data from their institution's implementation of a studio class, instructors could refer to the literature on their specific studio style. For example, the literature on SCALE-UP, a common studio implementation, shows that students in SCALE-UP achieved normalized gains on a conceptual inventory twice that of students in traditional classes [13]. A second form of evidence that could be effective at gaining student agreement is evidence that students will have positive experiences in the studio class. This would combine the primary influence on student agreement that actually occurred in our study (experience) with the primary influence that students indicate would influence their agreement (evidence). As the students in this study cited their experiences with the class as the reason their agreement changed throughout the semester, if instructors highlight these positive experiences as they happen, they may be able to positively influence student agreement. These experiences may be thought of as evidence of the studio format's effectiveness.

\section{ACKNOWLEDGMENTS}

This work was supported by the National Science Foundation (Grant Nos. DUE 1347510, 1347515, and 1347527).

[8] Science Education Initiative at the University of Colorado, Boulder. Retrieved from http://www.colorado.edu/sei/facresources/framing.html

[9] J. Aronson, The qualitative report 2, 1 (1995).

[10] J. Cohen, Ed. and Psych. Meas., 20, 1 (1960).

[11] N. Mercer, (Multilingual matters, 1995).

[12] M. T. Hora, J. Bouwma-Gearhart and H. J. Park, WCER Working Paper, (2014).

[13] R. J. Beichner, et al., Research-Based Reform of University Physics 1, 1 (2007). 